\title{
Gas-Phase and Aqueous Photocatalytic Oxidation of Methylamine: The Reaction Pathways
}

\author{
Anna Kachina, ${ }^{1}$ Sergei Preis,, ${ }^{1}$ German Charles Lluellas, ${ }^{2}$ and Juha Kallas ${ }^{1}$ \\ ${ }^{1}$ Department of Chemical Engineering, Lappeenranta University of Technology, P.O. Box 20, 53851 Lappeenranta, Finland \\ ${ }^{2}$ Department of Chemical Engineering, University of Barcelona, c/Martí i Franquès 1-11, 08028 Barcelona, Spain
}

Received 19 April 2007; Accepted 26 June 2007

Recommended by Panagiotis Lianos

Photocatalytic oxidation (PCO) of methylamine (MA) on titanium dioxide in aqueous and gaseous phases was studied. A simple batch glass reactor for aqueous PCO and an annular continuous flow reactor for the gas-phase PCO were used. Maximum aqueous PCO efficiency was achieved in alkaline media. Two mechanisms of aqueous PCO_decomposition to formate and ammonia, and oxidation of organic nitrogen directly to nitrite-lead ultimately to $\mathrm{CO}_{2}$, water, ammonia, and nitrate: formate and nitrite were observed as intermediates. A part of the ammonia formed in the reaction was oxidized to nitrite and nitrate. Volatile PCO products of MA included ammonia, nitrogen dioxide $\left(\mathrm{NO}_{2}\right)$, nitrous oxide $\left(\mathrm{N}_{2} \mathrm{O}\right)$, carbon dioxide, and water. Thermal catalytic oxidation (TCO) resulted in the formation of ammonia, hydrogen cyanide, carbon monoxide, carbon dioxide, and water. The gas-phase PCO kinetics is described by the monomolecular Langmuir-Hinshelwood model. No deactivation of $\mathrm{TiO}_{2}$ catalyst was observed.

Copyright (c) 2007 Anna Kachina et al. This is an open access article distributed under the Creative Commons Attribution License, which permits unrestricted use, distribution, and reproduction in any medium, provided the original work is properly cited.

\section{INTRODUCTION}

Monomethylamine (MA) is one of the possible photocatalytic oxidation (PCO) products of an eco-toxicant causing great concern; unsymmetrical dimethylhydrazine $\left(\left(\mathrm{CH}_{3}\right)_{2} \mathrm{~N}-\mathrm{NH}_{2}, \mathrm{UDMH}\right)$, used mostly as a component of rocket propellants, and also in chemical synthesis, as a stabilizing organic fuel additive, an absorbent for acid gases, and in photography [1]. The present research is part of a broader study targeting the disclosure of the reaction pathways in PCO of UDMH; the results of which will be presented later.

Conventional strategies for polluted water treatment have certain drawbacks. While the combination of nitrification and denitrification can theoretically deal with nitrogencontaining waste streams, it is, however, limited by having to cope with widely changing concentrations of contaminants and sensitivity of bacteria. Adsorption and reverse osmosis can be applied but, because of its low efficiency, a subsequent waste treatment has to follow [2]. In the gas phase, a common industrial practice is incineration, which for nitrogencontaining compounds may result in the formation of nitrogen oxides such as $\mathrm{NO}, \mathrm{NO}_{2}$, and possibly $\mathrm{N}_{2} \mathrm{O}$, contributing to the formation of photochemical smog, the greenhouse effect, and stratospheric ozone depletion. To mitigate these unwanted environmental effects equipment modifications, selective noncatalytic and catalytic reduction processes have been required in order to reduce $\mathrm{NO}_{\mathrm{x}}$ emissions [3]

Methylamine decomposition under oxidative conditions has been reported by different researchers; an exhaustive review was published by Kantak et al. [3]. It has been reported that at $623 \mathrm{~K}$, a greater part of MA is initially converted to $\mathrm{NH}_{3}$, with a small fraction forming $\mathrm{NO}_{\mathrm{x}}$ increasing with the increased $\mathrm{O}_{2}$ concentration. At low temperatures, around $523 \mathrm{~K}$, hydrogen cyanide $(\mathrm{HCN})$ is not formed in appreciable quantities, due to early $\mathrm{C}-\mathrm{N}$ bond scission. At higher temperatures (1160-1600 K), however, $\mathrm{HCN}$ has been observed as a product of MA thermal decomposition [4]. Higashihara et al. [5] suggested that the MA thermal decomposition may be a combination of two pressure- and temperature-dependent processes: the unimolecular scission of the $\mathrm{C}-\mathrm{N}$ bond and the stripping of four $\mathrm{H}$ atoms from the parent molecule to form $\mathrm{HCN}$ and $\mathrm{H}_{2}$.

Photocatalytic oxidation (PCO) over titanium dioxide may present a potential alternative to the air and polluted water treatment strategies mentioned above as it has advantages such as the ambient conditions at which the PCO reaction proceeds effectively, although higher temperatures may be also applied. Ameen et al. [6] reported that rapid gasphase PCO of MA produced a minor amount of $\mathrm{NO}_{\mathrm{x}}$ and their study of surface intermediates suggested the formation of nitrile bonds. 


\section{EXPERIMENTAL METHODS}

\subsection{Aqueous phase}

Monomethylamine 40\% wt aqueous solution (Aldrich) was used in all tests. 2-M sulphuric acid and 4-M sodium hydroxide were used to adjust the solution to the required $\mathrm{pH}$. The $\mathrm{pH}$ correction every even hour of treatment was sufficient to keep this parameter constant within decimal increment precision. The titanium dioxide powder used was Degussa P25.

A thermostatted 0.2 -L batch glass reactor, inner diameter $100 \mathrm{~mm}$, aperture $40 \mathrm{~m}^{2} \mathrm{~m}^{-3}$, equipped with a magnetic stirrer was used for the PCO of MA. All experiments were compared with reference samples under identical conditions except UV-radiation. A 365-nm 15-W low-pressure mercury UV-lamp (Phillips TLD) was positioned horizontally over the reactor. The UV-irradiance was about $0.37 \mathrm{~mW} \mathrm{~cm}^{-2}$, measured with a UVX radiometer at a distance corresponding to the level of the reactor's surface. The preliminary experiments showed that the 365-nm near-UV light did not exhibit an activity in decreasing MA concentration in aqueous phase.

The adsorption experiments with MA were carried out at concentrations of 100 and $200 \mathrm{mg} \mathrm{L}^{-1}$. A fixed amount of titanium dioxide of $1 \mathrm{~g} \mathrm{~L}^{-1}$ was placed in the flasks with magnetic stirrers for 24 hours at $298 \mathrm{~K}$. The measurements of MA adsorption on $\mathrm{TiO}_{2}$ were carried out using total organic carbon (TOC) measurements in liquid phase before and after adsorption by means of the TOC analyzer Shimadzu TOC 5050A. The adsorption experiments were carried out at $\mathrm{pH}$ from 2 to 11.7 .

A HACH DR/2000 spectrophotometer was used for chemical oxygen demand (COD) and ammonia analysis. The analyses were carried out in agreement with the standard procedure [7]. A Dionex DX-120 ion exchange chromatograph was used for the analysis of anions as intermediate and end products - nitrate, nitrite, and formate concentrations. The species were identified by comparing their retention peaks with those of standard anion solutions.

\subsection{Gas phase}

Gas-phase PCO of MA over UV-illuminated $\mathrm{TiO}_{2}$ was studied using an annular photocatalytic reactor having an inner diameter of $32 \mathrm{~mm}$. The reactor's length was $165 \mathrm{~mm}$ and the total volume of the empty space of the reactor was $55 \mathrm{~mL}$. The annular gap between the wall of the lamp and the inner wall of the reactor was $3.5 \mathrm{~mm}$. A 365-nm 15-W low-pressure mercury UV-lamp (Sylvania, UK) was positioned coaxially in the reactor; the diameter of the lamp was $25 \mathrm{~mm}$. The preliminary experiments carried out with no $\mathrm{TiO}_{2}$ catalyst applied showed that the 365-nm light did not exhibit an activity in decreasing MA concentration in gaseous phase.

The inner wall of the reactor was coated with $\mathrm{TiO}_{2}$ (Degussa P25) by rinsing with a $\mathrm{TiO}_{2}$ aqueous suspension, repeated 25 times, and each rinse was followed by drying. The reactor was assembled with the lamp after the catalyst had been attached to the reactor's wall. Approximately $0.3 \mathrm{~g}$ of $\mathrm{TiO}_{2}$ coated about $197 \mathrm{~cm}^{2}$ of the reactor $\left(1.5 \mathrm{mg} \mathrm{cm}^{-2}\right)$. The irradiance of the UV-lamp was measured with a UVX radiometer at a distance of $3.5 \mathrm{~mm}$ from the lamp and averaged about $3.8 \mathrm{~mW} \mathrm{~cm}^{-2}$. The reactor was used in a continuous flow mode.

In the experiments an evacuated gas cylinder was first filled with the desired amount of gaseous MA (Aldrich) through an injection port, and then filled with synthetic air $\left(20 \% \mathrm{O}_{2}, 80 \% \mathrm{~N}_{2}\right)$. The air stream containing MA was blended with diluent gas to deliver the desired volatile organic compound concentration to the reactor. The temperature in the reactor during the PCO reactions was maintained at 353 and $373 \mathrm{~K}$. The temperature was adjusted with heating tape wrapped around the reactor. The tape was controlled with a temperature regulator Omega CN 9000A with a $\mathrm{K}$ type thermocouple. The temperature deviations did not exceed $\pm 1 \mathrm{~K}$.

The gas flow rate was $3.03 \mathrm{~L} \mathrm{~min}^{-1}$, which made the contact time equal to 1.1 second. This contact time was sufficient to reliably register the difference between MA concentrations in the inlet and outlet streams, keeping that difference within 30 to $60 \%$ limits. The reaction products were analyzed by a Perkin Elmer 2000 FT-IR spectrometer equipped with a Sirocco $10.6-\mathrm{m}$ gas cell. Inlet concentrations of MA varied from 90 to $560 \mathrm{ppmv}\left(4.02 \cdot 10^{-3}\right.$ to $\left.2.50 \cdot 10^{-2} \mathrm{~mol} \mathrm{~L}^{-1}\right)$. No humidity was introduced to the air stream.

The experiments on thermal catalytic decomposition of MA were conducted in the dark at $573 \mathrm{~K}$. At lower temperatures, no measurable decrease in MA concentration was observed. The total volume of the reactor was increased to $0.105 \mathrm{~L}$, which at a gas flow rate of $3.03 \mathrm{~L} \mathrm{~min}^{-1}$ made the contact time as long as 2.1 seconds.

\section{RESULTS AND DISCUSSION}

\subsection{Aqueous PCO of MA}

The aqueous PCO efficiency for MA was studied dependent on $\mathrm{pH}$. Total organic carbon (TOC) appeared to be a viable parameter since the only detected carbon-containing byproduct, formic acid, observably reacts faster than the parent compound, thus making MA ultimately mineralized in PCO reactions. The PCO efficiency $E$ was defined as the decrease in TOC divided by the amount of energy reaching the surface of the treated sample:

$$
E=\frac{\Delta c \cdot V \cdot 1000}{I \cdot s \cdot t}
$$

where $E=$ PCO process efficiency, $\mathrm{mg} \mathrm{W}^{-1} \mathrm{~h}^{-1} ; \Delta c=$ TOC decrease, $\mathrm{mgC} \mathrm{L}^{-1} ; V=$ the volume of sample to be treated, $\mathrm{L} ; I=$ irradiation intensity, $\mathrm{mW} \mathrm{cm}^{-2} ; s=$ solution irradiated surface area, $\mathrm{cm}^{2} ; t=$ treatment time $(\mathrm{h})$.

The results of PCO of MA solutions are presented in Figure 1. The lowest efficiency was observed within the $\mathrm{pH}$ range from 2 to 7: a minor decrease in the MA concentration was observed in low-pH PCO. A drastic increase in the PCO efficiency was observed with $\mathrm{pH}$ increasing from about 7 to 11.7. At $\mathrm{pH} 11.9-12.5$, the MA volatility was high enough that no MA was found in reference samples after about eight hours of treatment: the target compound had 


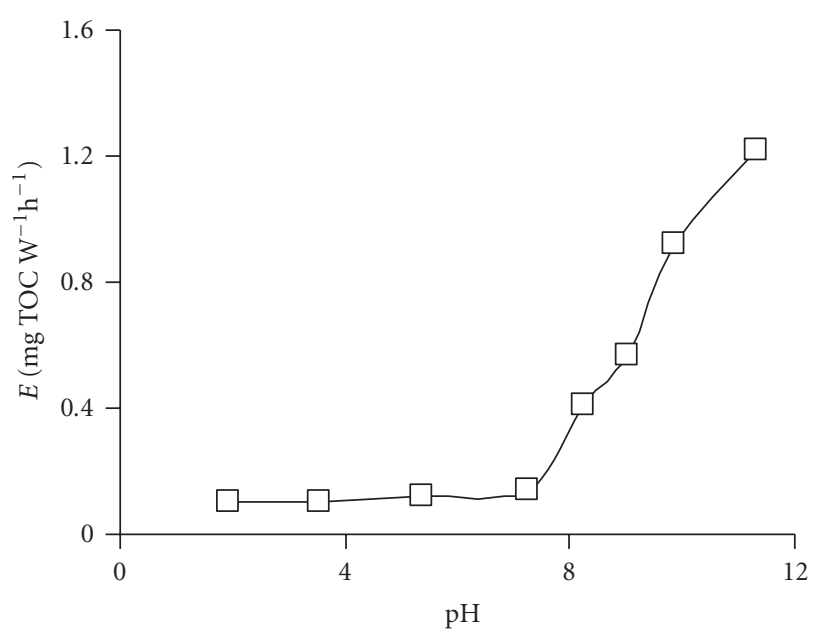

FIgURE 1: Dependence of PCO efficiency on pH for synthetic solution of MA (the efficiency was calculated for 24-hour treatment of MA solutions).

simply volatized from the solution. This circumstance made proper TOC measurements in the PCO-treated samples impossible: the residual TOC had no reference with which it could be compared.

The low efficiency in acidic media may be explained by poor adsorption of protonated MA molecules on the protonated $\mathrm{TiO}_{2}$ surface. The pKa value for MA is 10.62 at $298 \mathrm{~K}$, that is, MA is a strong base. This value shows that the amount of protonated MA-ions exceeds the amount of nonprotonated molecules, especially under acidic medium conditions. Positively charged protonated MA molecules are electrostatically repeled by the positively charged $\mathrm{TiO}_{2}$ surface (the isoelectric point $\mathrm{pHzpc}$ for $\mathrm{TiO}_{2}$ is 6.3) resulting in poor PCO. The PCO efficiency showed an increase with increasing $\mathrm{pH}$ from 7 to 11.7, which could be explained, probably, by the closer attraction between the negatively charged $\mathrm{TiO}_{2}$ surface and the protonated MA molecules. The electrostatic attraction, however, does not mean adsorption of $\mathrm{MA}$ on the $\mathrm{TiO}_{2}$ surface. Therefore, the increase in the PCO efficiency of MA at alkaline $\mathrm{pH}$ may be explained by the oxidation of MA with the $\mathrm{OH}$-radicals generated from $\mathrm{OH}$-ions.

The adsorption experiments for MA showed negligible adsorption over the $\mathrm{pH}$ range 2 to 11.7; within the experimental error interval, the concentration of MA in the solution did not change as a result of addition of the photocatalyst. This leads to the conclusion that the adsorption of MA on $\mathrm{TiO}_{2}$ did not play a crucial role in the PCO also under alkaline conditions, where PCO showed a higher efficiency.

Neither anionic intermediates were observed among the products of aqueous $\mathrm{PCO}$ of MA at the $\mathrm{pH}$ range from 2 to 7 , identified by means of anionic ion-exchange chromatograph nor ammonia was found at the same $\mathrm{pH}$ range. Nitrite, nitrate, ammonia, and formate were identified as PCO products of MA at $\mathrm{pH}$ above 7.0. A low concentration of nitrate can be observed at $\mathrm{pH} 9$, indicating only slight oxidation of MA occurring at this $\mathrm{pH}$. The amount of nitrite and nitrate increased with increasing $\mathrm{pH}$. The maximum PCO efficiency

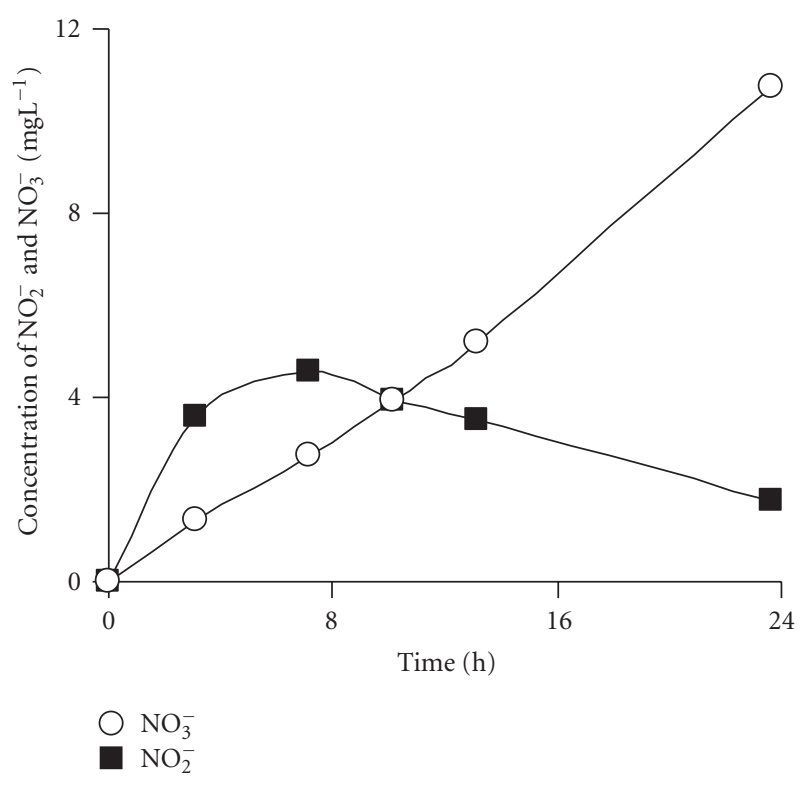

FIgure 2: Formation of $\mathrm{NO}_{3}^{-}(\bigcirc), \mathrm{NO}_{2}^{-}(\mathbf{\square})$ in PCO of MA at $\mathrm{pH}$ 11 and initial concentration of MA $100 \mathrm{mg} \mathrm{L}^{-1}$.

was observed at $\mathrm{pH}$ 11.7, which then may be considered to be an optimum $\mathrm{pH}$ for the PCO of MA.

Figure 2 shows the formation of nitrite and nitrate ions in an alkaline solution during aqueous PCO of MA. In the first 7 hours of PCO of MA, both nitrite and nitrate ion concentration increased. After that, the nitrate ion concentration increased in contrast to the decrease in the nitrite ion concentration, which can be explained by conversion of nitrite to nitrate.

The formation of formate and ammonia was observed in an alkaline medium. The higher the $\mathrm{pH}$, the more formate was observed in the treated samples.

The formate concentration was about 8.5 times lower than the initial concentration of MA, which indicates that formate was not accumulated due to its high reactivity on UV-irradiated $\mathrm{TiO}_{2}$ surface.

At the end of the experiment, the formate concentration decreased. The greatest amount of ammonia was observed at $\mathrm{pH} 11$. The curve of the ammonia concentration versus treatment time reached a maximum after somewhere between 4 and 20 hours of treatment, decreasing afterwards most probably due to ammonia oxidation to nitrite, as pointed out also by other authors [8-11].

Figure 3 illustrates the relationship between ammonia and formate in the treated samples at $\mathrm{pH} \mathrm{11.} \mathrm{Both} \mathrm{formate}$ concentration and ammonia concentration reached a maximum followed by a gradual decrease; it is supposed that the formate is oxidized to $\mathrm{CO}_{2}$ and $\mathrm{H}_{2} \mathrm{O}$ by PCO.

It is interesting to note the low concentration of formate compared to the residual MA concentration; the TOC analysis showed slow mineralization of MA, thus confirming a faster decomposition of formate than MA (see Figure 3). The profile of the TOC degradation shows no accumulation of organic byproducts. The inflection point of the formate 
concentration is noticeably lower than that of MA, which also confirms that the degradation of MA is slower than the degradation of formate.

The fact that the concentration of ammonia is lower than that of formate indicates possible ammonia oxidation and direct oxidation of organic nitrogen to nitrite. The $\mathrm{pH}$ tending to decrease in the experiments also indicates possible free ammonia volatilization, mineralization of formate, and consumption of $\mathrm{OH}$-ions in $\mathrm{PCO}$ reactions.

The degradation of ammonia to nitrite is enhanced at high $\mathrm{pH}$ range, which is consistent with previous findings [12-14]. When the $\mathrm{pH}$ increased from 10.3 to 11.4 , the amount of nitrite ion formed increased from $0.7 \mathrm{mg} \mathrm{L}^{-1}$ at the maximum concentration point at 8 hours of the treatment to $9 \mathrm{mg} \mathrm{L}^{-1}$ at the same time; the $\mathrm{pH}$ was varied at 0.2 increments and the concentration of nitrite increased consistently. Later on in the experiments, the concentration of nitrite decreased at all $\mathrm{pH}$ values (see also Figure 2).

Figure 2 indicates that nitrite seems to be oxidized easily to nitrate, although the conversion of ammonia or MA, or both, to nitrite seems to proceed fast: the concentration of nitrite exceeds the concentration of ammonia at the same time of treatment (see Figures 2 and 3).

The general trends of oxidation of MA are summarized by (2):

$$
\begin{aligned}
& \mathrm{CH}_{3}-\mathrm{NH}_{2} \stackrel{h v, \mathrm{OH}^{\bullet}}{\longrightarrow} \mathrm{NH}_{3}+\mathrm{CH}_{2}^{\bullet}, \\
& \mathrm{NH}_{3} \stackrel{\mathrm{OH}^{\bullet}}{\longrightarrow} \mathrm{NO}_{2}^{-} / \mathrm{NO}_{3}^{-}+\mathrm{H}_{2} \mathrm{O}, \\
& \mathrm{CH}_{2} \stackrel{\mathrm{OH}^{\bullet}}{\longrightarrow} \mathrm{HCOOH}+\mathrm{H}_{2} \mathrm{O}, \\
& \mathrm{HCOOH} \stackrel{\mathrm{OH}^{\bullet}}{\longrightarrow} \mathrm{CO}_{2}+\mathrm{H}_{2} \mathrm{O}, \\
& \mathrm{CH}_{3} \mathrm{NH}_{2} \stackrel{h v, \mathrm{OH}^{\bullet}}{\longrightarrow} \mathrm{NO}_{2}^{-} / \mathrm{NO}_{3}^{-}+\mathrm{HCOOH}+\mathrm{H}_{2} \mathrm{O} .
\end{aligned}
$$

\subsection{Gas-phase PCO of MA}

Since the products of the thermal catalytic oxidation (TCO) of MA have been established previously [3-5], the experiments in the dark at elevated temperature $573 \mathrm{~K}$ were carried out to verify the reliability of the measurements. The TCO of MA proceeded along two reaction pathways: dehydrogenation of the MA molecule with hydrogen cyanide formed as a product through the methanimine stage, and $\mathrm{C}-\mathrm{N}$ bond scission forming ammonia and the carbon mineralization products. The volatile products leaving the reactor included ammonia, hydrogen cyanide, carbon dioxide, and water, which is consistent with the findings of Kantak et al. [3].

The PCO volatile products, visible in the infrared spectra, included ammonia, nitrogen dioxide, nitrous oxide, carbon dioxide, and water. One of the infrared spectra of the PCO products of MA is shown in Figure 4. The MA-ammonia balance showed a fraction of a percent discrepancy, that is, nitrogen oxides appeared in small amounts.

Formation of nitrous oxide $\left(\mathrm{N}_{2} \mathrm{O}\right)$ was described in Pérez-Ramíres et al. [15] as a result of PCO of ammonia in the presence of nitrogen oxide. Nitrogen oxide (NO),

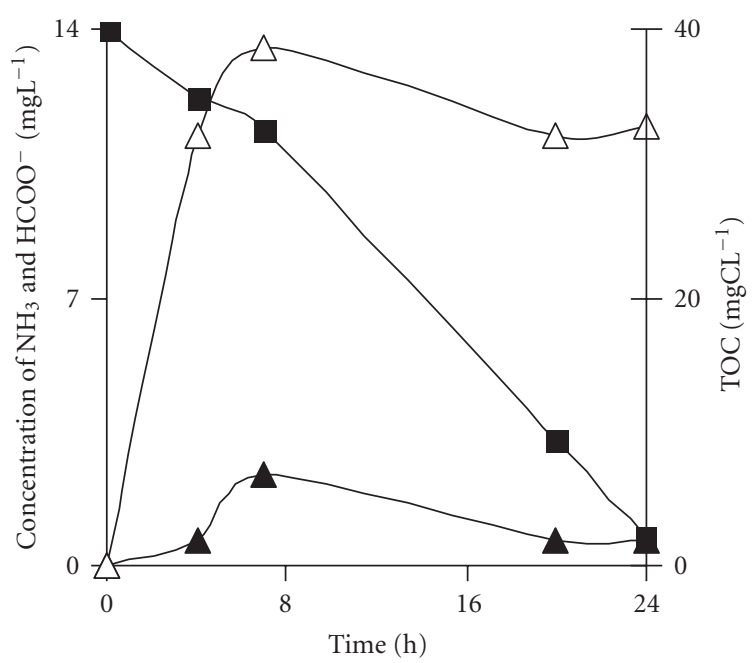

TOC degradation
$\triangle$ Formation of $\mathrm{NH}_{3}$
$\triangle$ Formation of $\mathrm{HCOO}^{-}$

Figure 3: TOC degradation ( $\mathbf{\square})$, formation of $\mathrm{NH}_{3}(\boldsymbol{\Delta})$ and $\mathrm{HCOO}^{-}(\Delta)$ in $\mathrm{PCO}$ of MA at $\mathrm{pH} 11$, and initial concentration of MA $100 \mathrm{mg} \mathrm{L}^{-1}$.

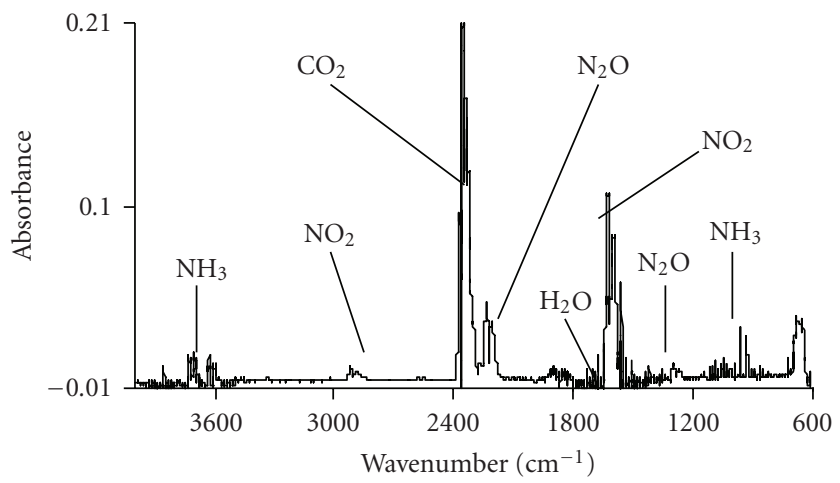

FIGURE 4: FT-IR spectrum of the outlet flow containing PCO products of MA.

presumably formed in the PCO reaction from ammonia, was partially oxidized further to nitrogen dioxide and partially reacted with residual ammonia forming nitrous oxide $\left(\mathrm{N}_{2} \mathrm{O}\right)$. Nitrogen oxide (NO) was not seen among the reaction products due to its high reactivity,

$$
\begin{aligned}
& \mathrm{CH}_{3}-\mathrm{NH}_{2} \stackrel{h^{+}, \mathrm{O}_{2}}{\longrightarrow} \mathrm{NH}_{3}+\mathrm{CH}_{2}^{\bullet}+\mathrm{H}_{2} \mathrm{O} \text {, } \\
& \mathrm{NH}_{3} \stackrel{h^{+}, \mathrm{O}_{2}}{\longrightarrow} \mathrm{NO} / \mathrm{NO}_{2}+\mathrm{H}_{2} \mathrm{O}, \\
& \mathrm{NH}_{3(\text { ads })}+\mathrm{NO} \stackrel{h^{+}, \mathrm{O}_{2}}{\longrightarrow} \mathrm{N}_{2} \mathrm{O}+\mathrm{H}_{2} \mathrm{O} \text {, } \\
& \mathrm{CH}_{2}^{\bullet} \stackrel{h^{+}, \mathrm{O}_{2}}{\longrightarrow} \mathrm{HCOOH}, \\
& \mathrm{HCOOH} \stackrel{h^{+}, \mathrm{O}_{2}}{\longrightarrow} \mathrm{CO}_{2}+\mathrm{H}_{2} \mathrm{O} \text {. }
\end{aligned}
$$




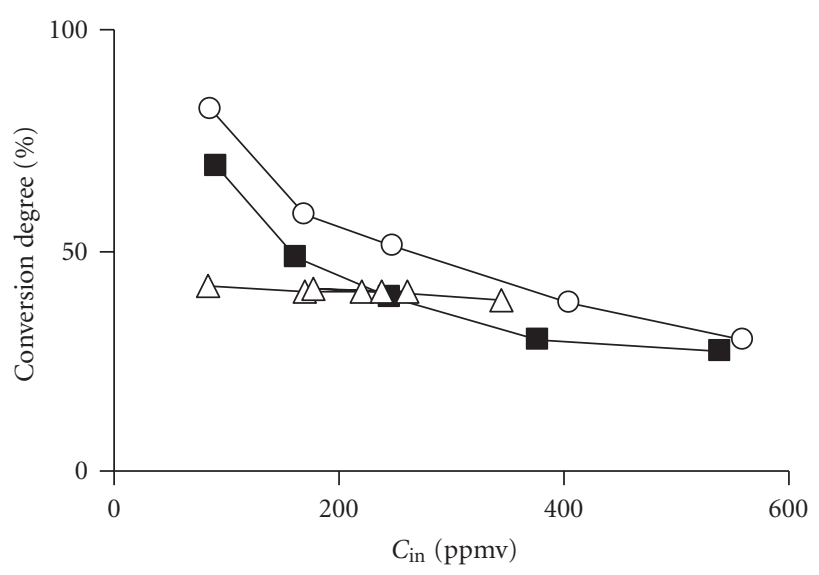

$353 \mathrm{~K}(\mathrm{PCO})$

$\bigcirc 373 \mathrm{~K}(\mathrm{PCO})$

$\triangle 573 \mathrm{~K}(\mathrm{TCO})$

FIgURE 5: PCO and TCO conversion of MA versus inlet concentrations at (ם) 353 (PCO), ( 373 (PCO), and $(\Delta) 573 \mathrm{~K}(\mathrm{TCO})$.

\section{PCO and TCO kinetics}

As previously established by Kim and Hong [16], the complex mechanisms of photocatalytic reactions are difficult to describe for an extended reaction time in a simple model. Therefore, the kinetic modeling is usually restricted to the analysis of the initial rate of photocatalytic degradation. This can be obtained from a minimum detectable conversion of the reactant at a minimum contact time.

The Langmuir-Hinshelwood (L-H) model of the monomolecular reaction kinetics, the reciprocal form of which is presented by (4), has been widely used for gas-phase photocatalytic reactions,

$$
\frac{1}{r_{0}}=\frac{1}{k K} \frac{1}{C_{0}}+\frac{1}{k}
$$

where $r_{0}$ is the initial reaction rate $\left(\mathrm{mol} \mathrm{m}^{-3} \mathrm{~s}^{-1}\right), C_{0}$ is the inlet concentration of the reactant $\left(\mathrm{mol} \mathrm{m}^{-3}\right), k$ is the reaction rate constant $\left(\mathrm{mol} \mathrm{m}^{-3} \mathrm{~s}^{-1}\right)$, and $K$ is the Langmuir adsorption coefficient $\left(\mathrm{m}^{3} \mathrm{~mol}^{-1}\right)$.

Figure 5 shows the conversion of MA as a result of PCO versus inlet reactant concentration: the conversion varies inversely with the inlet concentration at the tested temperatures, that is, the process is obviously not of the first order and may fit to the L-H description.

The initial rate of MA PCO was observed to be consistent with the L-H kinetic model, which is in agreement with the findings of Ameen et al. [6]. A linear plot of $r_{0}^{-1}$ versus $C_{0}^{-1}$ (see (4)) is shown in Figure 6, from which $k$ and $K$ values were obtained. Reaction rate constants and the Langmuir adsorption coefficient for PCO of MA at the tested temperatures are given in Table 1.

One can see the reaction rate constant increasing and the adsorption coefficient decreasing with increasing temperature, making the apparent reaction rate practically independent of the temperature within the tested range.

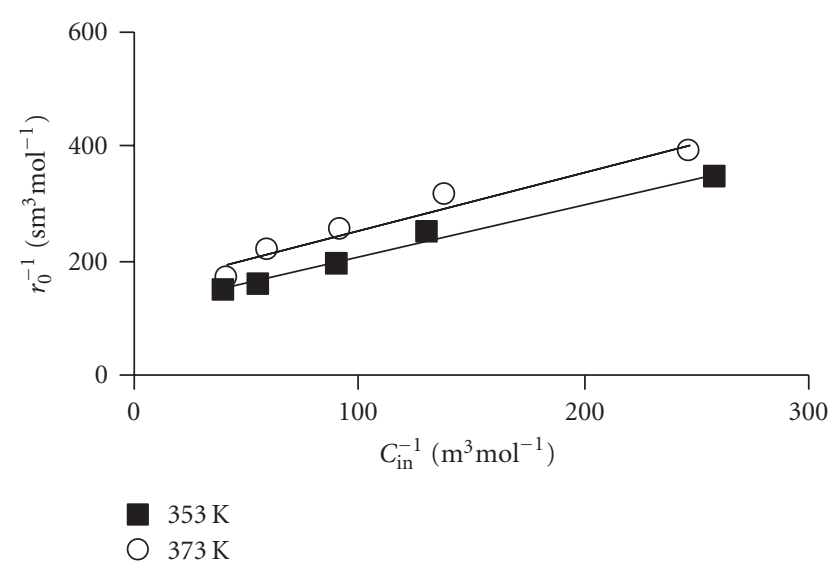

FIgure 6: Reciprocal PCO reaction rates on $\mathrm{TiO}_{2}$ versus the reciprocal MA initial concentrations at $(\square) 353$ and $(\bigcirc) 373 \mathrm{~K}$.

TABLE 1: Reaction rate constants and Langmuir adsorption coefficients for PCO of MA.

\begin{tabular}{c|cc}
\hline Temperature $(\mathrm{K})$ & $k\left(\mathrm{mmol} \mathrm{m}^{-3} \mathrm{~s}^{-1}\right)$ & $K\left(\mathrm{~m}^{3} \mathrm{~mol}^{-1}\right)$ \\
\hline 353 & $6.6 \pm 0.1$ & $148 \pm 1$ \\
373 & $8.7 \pm 0.1$ & $125 \pm 1$ \\
\hline
\end{tabular}

In contrast to PCO, TCO kinetic behavior indicated the first order process: the conversion degree varied proportionally with the inlet concentration of MA at $573 \mathrm{~K}$ (see Figure 5).

No indication of photocatalyst deactivation was observed in multiple (more than 100) experimental runs of 2 hours each, which is in agreement with the observations reported by Ameen et al. [6]. The authors may explain minor deactivation of the photocatalyst referring to the phenomenon reported by Kolinko et al. [17]: nitric acid, composed of negligible amount of transformed nitrogen, enhances the alkaline MA adsorption on the acidic $\mathrm{TiO}_{2}$ surface having organic nitrates, and ammonium nitrate also photocatalytically oxidized with no additional $\mathrm{HNO}_{3}$ formation. Slow, or zero after the first formation of nitric acid, accumulation of nitrates makes the catalyst deactivation rate also slow or zero.

\section{CONCLUSIONS}

\section{Aqueous PCO}

The present research showed the aqueous PCO of MA on a titanium dioxide catalyst to be successful only in alkaline media. The optimum $\mathrm{pH}$ was 11.7 , according to the PCO efficiency parameter. The two pathways of PCO of MAdecomposition to formate and ammonia, and oxidation of organic nitrogen directly to nitrite-lead ultimately to carbon dioxide, water, ammonia, and nitrate. Formate and nitrite were observed as the intermediates. Formate decomposes further to carbon dioxide and water; part of the ammonia reacts on the $\mathrm{TiO}_{2}$ surface to produce nitrite, which ultimately leads to nitrate. Nitrite is also formed directly from 
the MA molecule in a parallel reaction. The predominant role of OH-radicals in PCO of MA is presumed.

\section{Gas-phase PCO}

When considering the gas phase, methylamine is easily oxidized photocatalytically on UV-irradiated $\mathrm{TiO}_{2}$. The volatile PCO products of MA in the gas phase included ammonia, nitrogen dioxide, nitrous oxide, carbon dioxide, and water; the TCO products of MA at $573 \mathrm{~K}$ included ammonia, hydrogen cyanide, carbon dioxide, and water. The PCO reaction kinetics followed the Langmuir-Hinshelwood description. The photocatalyst demonstrated stable activity at temperature and concentration ranges tested in the experiments.

In both reactions, aqueous and gaseous phases, oxidized nitrogen species (nitrogen oxides in the gas phase, nitrite and nitrate anions in water) are formed through intermediate products, although ammonia prevails as the end product. No toxic cyanide is formed in the PCO reactions. The gas-phase reaction utilizes the radiation energy more effectively.

\section{ACKNOWLEDGMENT}

The authors express their gratitude to the Academy of Finland (program "Russia in Flux," project 208134) for financial support of the present research.

\section{REFERENCES}

[1] R. J. Lewis, Ed., Hawley's Condensed Chemical Dictionary, John Wiley \& Sons, New York, NY, USA, 13th edition, 1997.

[2] M. Klare, J. Scheen, K. Vogelsang, H. Jacobs, and J. A. C. Broekaert, "Degradation of short-chain alkyl- and alkanolamines by $\mathrm{TiO}_{2}$ - and $\mathrm{Pt} / \mathrm{TiO}_{2}$-assisted photocatalysis," Chemosphere, vol. 41, no. 3, pp. 353-362, 2000.

[3] M. V. Kantak, K. S. De Manrique, R. H. Aglave, and R. P. Hesketh, "Methylamine oxidation in a flow reactor: mechanism and modeling," Combustion and Flame, vol. 108, no. 3, pp. 235-265, 1997.

[4] S. M. Hwang, T. Higashihara, K. S. Shin, and W. C. Gardiner Jr., "Shock tube and modeling study of monomethylamine oxidation," Journal of Physical Chemistry, vol. 94, no. 7, pp. 28832889, 1990.

[5] T. Higashihara, W. C. Gardiner Jr., and S. M. Hwang, "Shock tube and modeling study of methylamine thermal decomposition," Journal of Physical Chemistry, vol. 91, no. 7, pp. 19001905, 1987.

[6] M. M. Ameen, M. Hossain, and G. B. Raupp, "Photocatalytic oxidation of airborne methylamine," Advances in Environmental Research, vol. 3, no. 1, pp. 1-14, 1999.

[7] L. S. Clesceri, "Standard methods for the examination of water and wastewater," in Chemical Oxygen Demand, L. S. Clesceri, A. E. Greenberg, and R. R. Trussel, Eds., American Public Health Association, Washington, DC, USA, 1989.

[8] S. Kim and W. Choi, "Kinetics and mechanisms of photocatalytic degradation of $\left(\mathrm{CH}_{3}\right)_{n} \mathrm{NH}_{4-n}{ }^{+}(0 \leq n \leq 4)$ in $\mathrm{TiO}_{2}$ suspension: the role of $\mathrm{OH}$ radicals," Environmental Science and Technology, vol. 36, no. 9, pp. 2019-2025, 2002.

[9] G. K.-C. Low, S. R. McEvoy, and R. W. Matthews, "Formation of nitrate and ammonium ions in titanium dioxide mediated photocatalytic degradation of organic compounds containing nitrogen atoms," Environmental Science and Technology, vol. 25, no. 3, pp. 460-467, 1991.

[10] P. Maletzky and R. Bauer, "The photo-fenton methoddegradation of nitrogen containing organic compounds," Chemosphere, vol. 37, no. 5, pp. 899-909, 1998.

[11] R. M. Alberici, M. C. Canela, M. N. Eberlin, and W. F. Jardim, "Catalyst deactivation in the gas phase destruction of nitrogen-containing organic compounds using $\mathrm{TiO}_{2} / \mathrm{UV}$ VIS," Applied Catalysis B, vol. 30, no. 3-4, pp. 389-397, 2001.

[12] X. Zhu, S. R. Castleberry, M. A. Nanny, and E. C. Butler, "Effects of $\mathrm{pH}$ and catalyst concentration on photocatalytic oxidation of aqueous ammonia and nitrite in titanium dioxide suspensions," Environmental Science and Technology, vol. 39, no. 10, pp. 3784-3791, 2005.

[13] A. Wang, J. G. Edwards, and J. A. Davies, "Photooxidation of aqueous ammonia with titania-based heterogeneous catalysts," Solar Energy, vol. 52, no. 6, pp. 459-466, 1994.

[14] E.-M. Bonsen, S. Schroeter, H. Jacobs, and J. A. C. Broekaert, "Photocatalytic degradation of ammonia with $\mathrm{TiO}_{2}$ as photocatalyst in the laboratory and under the use of solar radiation," Chemosphere, vol. 35, no. 7, pp. 1431-1445, 1997.

[15] J. Pérez-Ramírez, E. V. Kondratenko, V. A. Kondratenko, and M. Baerns, "Selectivity-directing factors of ammonia oxidation over PGM gauzes in the temporal analysis of products reactor: secondary interactions of $\mathrm{NH}_{3}$ and NO," Journal of Catalysis, vol. 229, no. 2, pp. 303-313, 2005.

[16] S. B. Kim and S. C. Hong, "Kinetic study for photocatalytic degradation of volatile organic compounds in air using thin film $\mathrm{TiO}_{2}$ photocatalyst," Applied Catalysis B, vol. 35, no. 4, pp. 305-315, 2002.

[17] P. A. Kolinko, D. V. Kozlov, A. V. Vorontsov, and S. V. Preis, "Photocatalytic oxidation of 1,1-dimethyl hydrazine vapours on $\mathrm{TiO}_{2}$ : FTIR in situ studies," Catalysis Today, vol. 122, no. 12, pp. 178-185, 2007. 


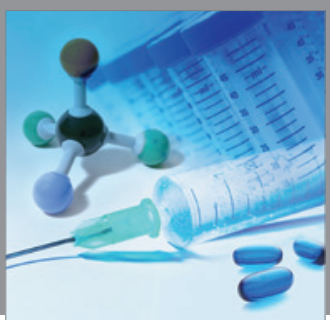

International Journal of

Medicinal Chemistry

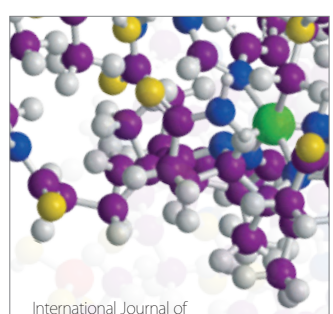

Carbohydrate Chemistry

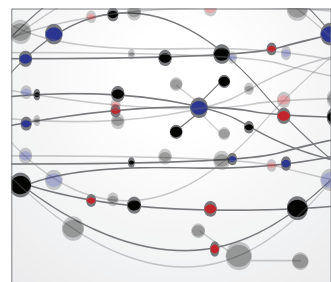

The Scientific World Journal
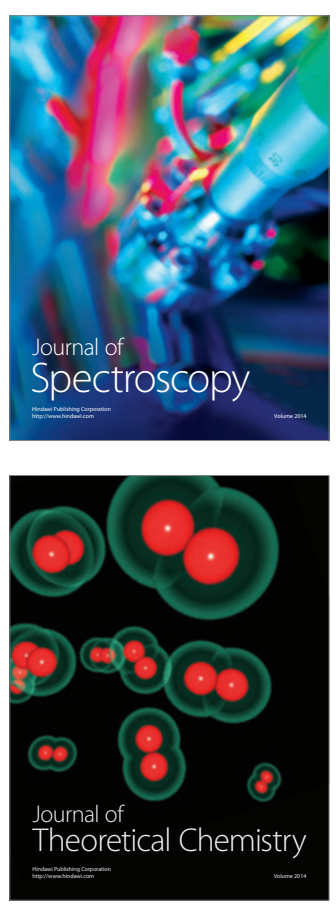
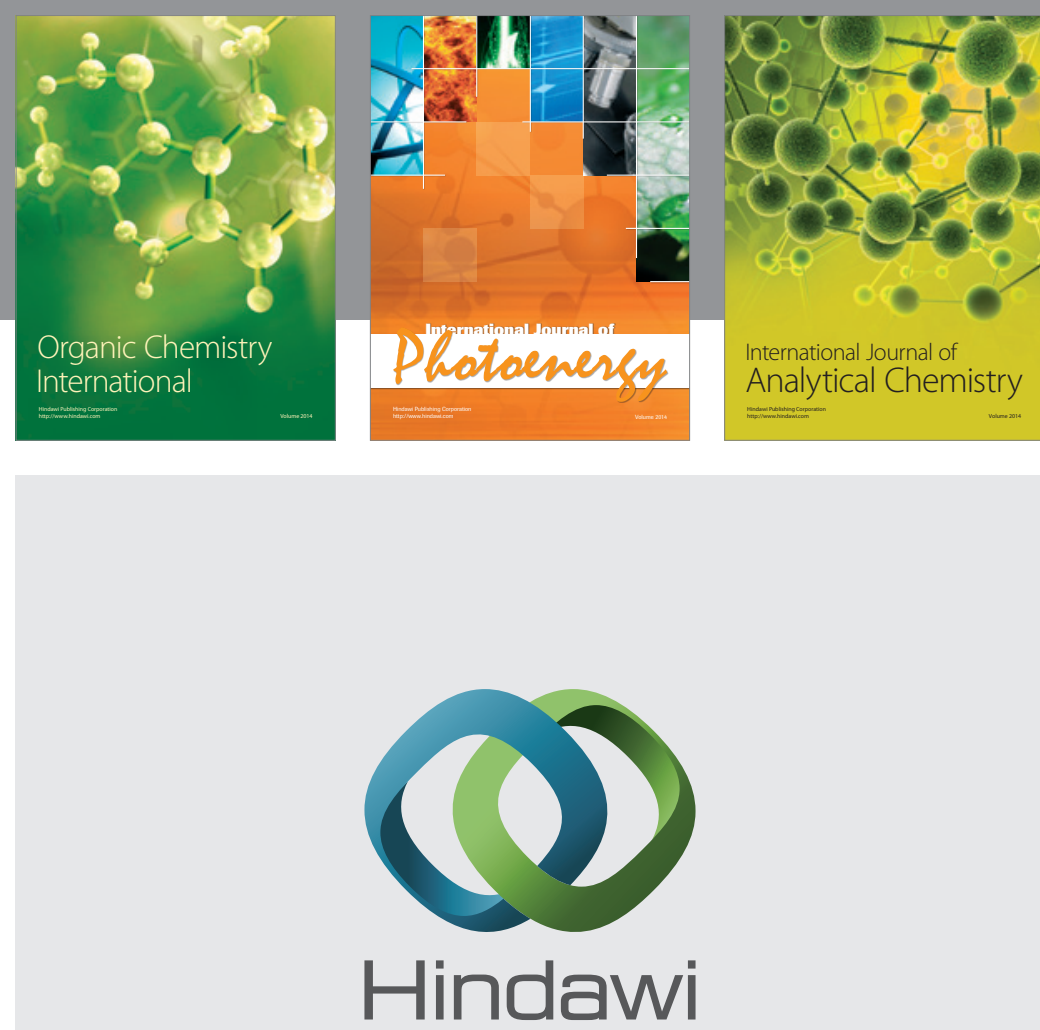

Submit your manuscripts at

http://www.hindawi.com
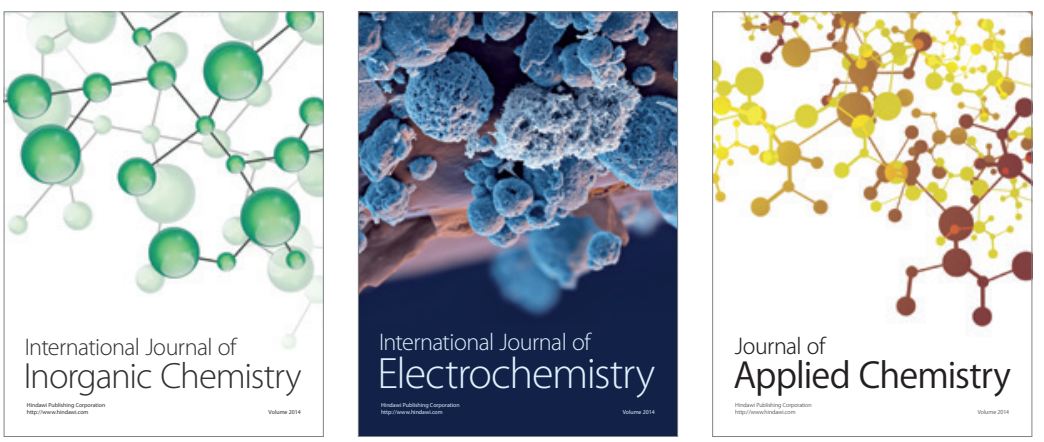

Journal of

Applied Chemistry
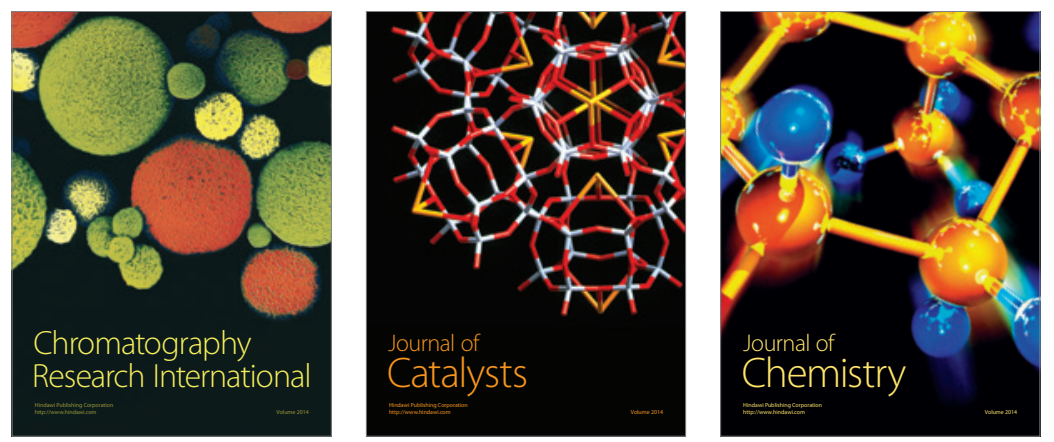
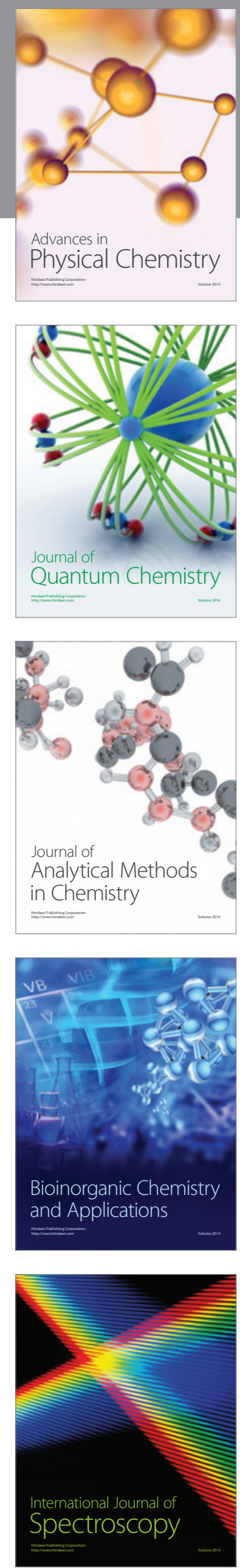